"Just to be perfectly clear then; by 30 July 2008 all members of the DCP groups MUST have registered with the GDC in order to be able to carry on working legally."

\title{
Lip service will no longer be enough
}

As the year dwindles and thoughts turn towards planning beyond the festive break into next year it inevitably means that we need to focus our attention on the registration of all Dental Care Professional (DCP) groups from 30 July 2008.

I am sure that $B D J$ readers will not be in the category of dentists who have overlooked such an important matter for their team members. Although there has been a lot of publicity from the General Dental Council (GDC), the DCP groups themselves and the dental press in general there are still many DCPs who have not yet registered and some very strange stories circulating about misunderstandings with regard to the process. Doubtless in the rich and gossipy tradition of urban myths the suggestion that some practices have decided 'not to be part of the scheme' must nevertheless have grown from some misinformation somewhere, however apparently amusing. It is, as we know, not optional.

Just to be perfectly clear then; by 30 July 2008 all members of the DCP groups MUST have registered with the GDC in order to be able to carry on working legally. Please ensure that your practice and your team members have completed this, preferably as soon as possible.

It is a now a cliché to write that this will cause a sea change in dentistry and the way in which it is delivered and perceived in this country. However, it is important to gaze over the immediately turbulent waters and try and anticipate what currents, eddies and maelstroms may swirl beyond the sandy shoreline of welcoming pleasantries. What is about to happen is the professionalisation of a larger number of people than currently populate the dental profession. They may not be dentists but they are, or will be, legally, ethically and morally regarded as professionals, a status which brings with it all the associated responsibilities, liabilities and benefits.

As leaders, dentists to date have therefore been responsible for leading a team comprising some professionals (hygienists/ therapists) and some non-professionals. From 31 July 2008 that balance will tip as the majority of the team will be registered professionals with protected titles. What will they come to expect of being 'upgraded'? What would any of us expect?

To begin with, greater respect. Brought forth in conflict with the usual panoply of abrupt reactions such as 'do you know who I am?', 'how dare you speak to me like that?' and 'I'll have you know I'm a professional person', a lack of regard for one's standing in society prompts righteous indignation. Expect more of this from team members for whom their new found standing will provide empowerment to anticipate greater consideration, be more forthcoming in negotiation and expect increased attention to their contributions. It is a shift of power and it will be uncomfortable. That is not to say that it should not happen, it is a valuable and necessary development for the oral health care profession but it will change the nature of the game. Forever. And one particular consequence is that it will cost more.

This is a factor that we have all seen coming but as yet have not fully acknowledged nor indeed attempted to calculate. We know that upgrading costs more. In aircraft - bigger seats, champagne; in hotels - larger bathrooms, chocolates on the pillow; professionally - greater education opportunities, better pay. Is it really reasonable to expect dental nurses, for example, to comply with their mandatory CPD requirements wholly in their own time and at their own expense? If we as dentists have to put our hands in our pockets to pay for indemnity cover, regulatory fees and membership dues don't we expect to be compensated? Surely we would all also think it reasonable that other professionals should receive equal treatment?

But we know how the pay-chain, like the food-chain, works. The employer pays, so the customer pays, so the patient pays. Inevitably this will mean that the cost of dental care will rise. To what extent have we 'reasonably' factored this into our budgets for 2008 and 2009? Oh, 2009, there's a date that rings a bell because of the next significant boundary in the funding of NHS dentistry. To what extent will UDA value, for example, be upwardly adjusted to take account of these fundamental changes that the profession, the regulators and society through Parliament have decided are 'good things'?

Clichés do not become clichés easily. They have to be true and they have to serve a hard and long apprenticeship to gain that accolade. We are dismissive of them but we rely on them heavily. Old sayings are similarly endowed with faint ridicule yet comforting security, so when from a dark recess you hear the sentiment 'fine words but look to purse' you'll know that the moment of true team work has arrived. Lip service will no longer be enough.

Stephen Hancocks OBE Editor-in-Chief

DOI: $10.1038 / b d j .2007 .1073$ 